\title{
Canadian Culture and Orthographic Word Forms: A Survey of Cultural Identity and Spelling Preferences
}

\author{
Michael Christian LeBlanc*
}

\begin{abstract}
Unlike most English speech communities with well-established spelling standards, historically English-speaking Canada has been split between British and American standards (Gregg, 1989), or has in some cases combined the British and American spelling structures (Pratt, 1993). As any native speaker of Canadian English could attest, some American standard forms, such as jewelry or story, seem ready to replace their British counterparts in the Canadian spelling lexicon, along with much older cases such as curb or tire. On the other hand, some researchers (Heffernan, Borden, Erath and Yang, 2010; Lipski, 1973) have pointed out the hostility toward American spelling forms since historically anti-Americanism is present in the Canadian linguistic landscape (see Pratt, 1993). This paper reviews the spelling choices of 26 Saskatchewan university students with respect to a group of 25 words known to be spelt differently in British and American English. The results are then correlated with those from a survey on attitudes toward Canadian culture (see section 3.1.3) and with the results from a brief "regional spelling test" (see Appendix B). Two questions are explored. First, to what degree can a correlation be found between the participants' preferences for the British spelling standard and positive attitudes toward Canadian culture? Second, what relationship can be discovered between the participants' spelling preferences and their knowledge of British and American spellings?
\end{abstract}

Keywords: Canadian Spelling; Orthography; Standards; Culture; Sociolinguistics

\section{Introduction}

\subsection{Standards and Standardisation}

Before discussing the historical landscape of the Canadian linguistic community, the basic idea and theory of linguistic standards should be discussed. From the outset, it can be seen that standards affect the linguistic value systems of people both as an abstraction and as a concrete application (Davies, 2012). As an abstraction, a standard may come to be considered as the best form of a language, while taking on nationalist qualities in the process (Vogl, 2012). On the other hand, since cultures that utilize

\footnotetext{
*BA Honours, Linguistics; Economics Minor, Recognition in Spanish, University of Saskatchewan 2014
}

Correspondence: mlebg987@gmail.com 
standard languages assume black-and-white attitude on questions of correct usage (Davies, 2012) there is also a need for a concrete written set of rules. Thus, there are four criteria ranging from the concrete to the abstract necessary for the formation of a standard (Holmes, 2013). According to Holmes, a standard:

1) must be codified and regularised;

2) must be influential or prestigious;

3) serves high variety functions (situations such as court, literature and administration in a nation);

4) is written (p.78).

Since full standardisation can only be properly ascribed to a dead language, standards are maintained by downplaying variation (Davies, 2012). While some amount of variation from speaker to speaker exists (Holmes, 2013) languages also cannot be learnt without prescription and imitation of a norm (Haas, 1982). The evolution and development of standards as a language "norm" for a speech community should then be analyzed in more detail.

According to Holmes (2013), what we come to know as a national standard always goes through a dynamic developmental process before attaining the social, economic, and political factors necessary to achieve a high level of social influence above its peers. For speech communities that develop a standard variety, there is a series of four steps: selection of the dialect, codification, elaboration in order to make sure it has the structures necessary to fulfil its social functions, and securing its acceptance across society (Holmes, 2013). With regard to selection, a given variety may have no particularly favourable linguistic features but simply exist as the dialect of the politically or socially prestigious (Holmes, 2013). In the case of English, the standard variety can use areas of influence and prestige, such as London and the east Midlands in the late middle ages (see Baugh and Cable, 2002). After a given dialect is selected, codification is required to document its standardised linguistic features (Holmes, 2013). This regularity, in the form of uniformity and determinacy, can come to be seen by "standard language cultures"1 as being ideal for all varieties (Davies, 2012). Elaboration occurs when a language develops new vocabulary to address the higher level functions required by a national language, thus developing (if needed) the lexicon

\footnotetext{
1 Note definition of standard language cultures by Milroy (2001): "Certain languages . . . are believed by their speakers to exist in standardized forms, and this kind of belief affects the way in which speakers think about their own language and about 'language' in general. We may say that speakers of these languages live in standard language cultures" (p. 530).
}

necessary to express itself in the socially prestigious domains of literature and administration (Holmes, 2013).

As discussed earlier, when acceptance of a standard is reached, a society can arrive at a situation where some ways of speaking are considered intrinsically correct. This means that people who speak or write differently may encounter discrimination to a greater or lesser extent. An example of possible discrimination is the research hypothesis of Hamp-Lyons and Davies (2008) that International English standards favour those with a metropolitan Anglophone education. While Hamp-Lyons and Davies could not find conclusive proof for their hypothesis, standards seem to be defined as much by those whom they exclude as they include. However, even in a modern context there are examples where more than one linguistic form can be considered acceptable, such as Norwegian (Vogl, 2012).

\subsection{A Brief History of English Orthography}

English has had its own history of standardization, up to the ambiguity of spelling choice that marks the Canadian English variant of today. Since each of the written and spoken norms constitutes a system to itself (Vacheck, 1982) it seems best to examine English orthography on its own merits, as distinct from the expansive and somewhat ambiguous concept of "English" - be it in a general or Canadian context.

With only a few exceptions (such as mathematics, semi-pictographic symbols in internet communication such as smilies, and logographic symbols such as ampersands) English uses an alphabetic system to present itself in a graphical, written form. The individual written symbols used to represent linguistic meaning are referred to as graphemes. To a varying degree (see Cook, 2014) these graphemes can represent sounds in a given language. However, due to the nature of sound change and the basic workings of an alphabet, multiple spelling forms are possible not only in cases when there are differences in actual word pronunciation from dialect to dialect, but also when there are no such differences, such as those we see in the British, Canadian, and American English paradigm.

For a brief introduction to the historical paradigm, English displaced both Latin and French as the most common written register in England beginning in the 15th century (Baugh \& Cable, 2002). At about the same time, the East Midlands dialect began to emerge as the English standard (Baugh \& Cable, 2002). There were three initial reasons for the rise of this dialect's status above others: its geographical location between the more northern and southern dialects; its population increase and relative prosperity; and the presence of Oxford and Cambridge 
universities, which gave the written variant social prestige (Baugh \& Cable, 2002). The most important factor, however, was the merger of the London English and the East Midlands dialects; this merger caused the resulting dialect to take on the political prestige of being the dialect spoken in the capital of England (Baugh \& Cable, 2002). From there, it began to spread, also due in no small part to William Caxton (who used the London dialect in his typesetting), and the first English printing press in 1476 (Baugh \& Cable, 2002).

The next major event, after the dialect was selected and arose to some prominence, was the actual orthographic "freezing." While in Old English there was relatively closer sound-symbol correspondence, in Middle English, things began to change; alterations in the phonological system such as the Great Vowel Shift (where English long vowels "shifted" or changed while short vowels remained the same) were not reflected in English orthography (Cook, 2014). Spelling ambiguity thus resulted in scenarios such as that of words ending in -our (such as rigour) where there were no fewer than nine different orthographic variations by the end of the 16th century: -or, our, -ur, -ure, -eur, -ore, -er, -oure, and -ir (Anson, 1990). At the same time, writers such as John Hart and Thomas Smith sought to bring back spelling-sound correspondence, but with limited success (Baugh \& Cable, 2002). According to Scragg (1974), stabilisation finally came in the 17th century as dictionaries came to rely not on general usage but on the spelling rules used by printers, who in turn might be obliged to rely on dictionaries when their forms conflicted. While English spelling has changed over the centuries (see Scragg 1974; Baugh \& Cable 2002), by 1650 spelling in the modern form was practically established (Baugh \& Cable 2002). The upshot of this particular development perhaps being best enunciated by Cook (2014): that we have modern English pronunciation with middle English spelling.

In the middle 18th century we see the arrival of Samuel Johnson's dictionary in 1755 for British English, while across the Atlantic in the newly formed United States of America Noah Webster's dictionaries (first in 1808, and again in 1828) set a slightly different orthographic standard. At this time, the United States had not merely won its revolutionary war with Britain, but had also launched several (failed) invasions into what remained of British North America (upper and lower Canada) between 1812-1815. As Merriam-Webster's official website informs us, Noah Webster was a staunch believer of developing the cultural independence of the new United States of America ("Noah Webster and America's First Dictionary," n.d.). Moreover, Ramsey (2012) argues that in completing this dictionary Noah Webster was actually engaged in an epideictic discourse in an attempt to unify the American people.

Setting aside lexicology and the extra-linguistic material within Webster's Dictionary, the most notable features of Webster's orthographic reform with respect to the subject of this paper are dropping the $u$ from -our in words like humour or colour; the presence of only a single $l$ (or $p$ ) when suffixing two syllable verbs (stressed on the first) like travelling or worshipping; and the changing of word final -ce constructions to -se such as defence ("Noah Webster's Spelling Reform," n.d.). Not surprisingly, British subjects might pass on Webster's spelling reforms, associating these reforms with Americanism (Pratt, 1993).

\subsection{The Canadian Perspective}

Chambers (1998) defines the Canadian accent as "urban, middle-class English as spoken by people who have been urban, middle-class Anglophones for two generations or more" (as cited in Dolinger, 2011, p. 4). Using this definition, Dolinger (2011) discusses the demographics of Standard Canadian English, revealing that $36 \%$ of the Canadian population are likely speakers. Moreover, Dolinger also reveals that spelling has not yet been standardised. We will then take a closer look at Canadian English orthography.

Since anti-American sentiments have existed since the formation of Canada as a nation in 1867 (Pratt, 1993), the choice between British and American spelling seems clear for Canadians, at least historically. Indeed, something resembling a Canadian standard was touched on by an 1890 order-in-council mandating "in all official documents... the English practice of -our endings shall be followed" (as cited in Pratt, 1993, p. 52). However, neither dictionaries nor style guides have settled on a definitive Canadian standard (Pratt, 1993; see Public Works and Government Services Canada, 1997), and economic influence from the United States is such that if a book is published in the United States, it may be re-edited with American spellings (Pratt, 1993, p. 57). The result of this linguistic confusion in terms of standardisation is that Canadian editors require proficiency in three styles: American, British, and the publisher's particular blend of the two (Pratt, 1993).

From an educational perspective, Dolinger (2011) states that even with a desire to teach Standard Canadian English, in the absence of a standard teachers are left to define Standard Canadian alone, and so arriving at conflicting conclusions (p. 6). The University of Saskatchewan English Department's Requirements for Essays states that "Canadian spelling is standard in Canada; British or American spelling is acceptable. Whichever form of spelling you choose, use it consistently throughout your essay" (2014, p. 4), while Saskatchewan public high school Aden Bowman's 2013-2014 student handbook states that 
the standard in Canada is not Canadian but British, though American is acceptable (p. 34). In the context of essay writing, there seems to be a tendency to consider a "mix" of dialectal variation (in this case, spelling variation) as somehow deviant or non-standard (see Davies, 2012).

Adding to the mix, the Translation Bureau on spelling (Public Works and Government Services Canada, 1997) offers two recommendations. One, use a Canadian dictionary, such as Canadian Oxford or Gage Canadian Dictionary to resolve the ambiguity - neither of which have staff currently researching Canadian lexicography due to closures and cutbacks by both Oxford and Gage (now Nelson) (Dolinger, 2011, p. 6). The second, mercifully, offers up a rule: along with a few American forms (namely in the case of -ize, -ization) mostly British forms are to be used (Public Works and Government Services Canada, 1997). In this context, we see a blend of the two perhaps being an inclination toward a Canadian standard. ${ }^{2}$

\subsection{Language Culture in Canada}

There have been many studies relating to different influences on what is considered "standard" spelling in Canada. Direct relationships have been found with the frequency of "Canadian" forms, usually considered to be more or less agreeing with the British standard 3 - including level of Education (Warkentyne, 1971), anti-Americanism (Heffernan et al., 2010; see Pratt 1993), a desire to show Canadian identity, the social prestige of sounding British, and a desire to show the "bona fide" origin of Canadian products (Lipski, 1971). The use has also been negatively correlated with the historical difficulty of printing typeset newspapers and the presence of automatic spellchecking software preset to American orthography (Shuttleworth, 2011). Further, when there is a desire to publish an item on both sides of the American-Canadian border, American expectations of "correct spelling" can influence publishers to use more American forms (see Pratt 1993). Spelling also seems to vary both by region within Canada (Ireland, 1979) and by time (Grue, 2013; Heffernan et al., 2010). This variation has been shown to extend to Canadian newspapers and style guides (Skorupska, 2013). Finally, in the case of bilingual signage, the influence of French seems

${ }^{2}$ For the purposes of this study, the author decided not to use this particular version of a "Canadian standard" to categorise participant responses: only British (taken as Canadian) versus American was used.

3 See Heffernan et al., 2010: "the discourse surrounding the indexation of identity by spelling variants tends to be framed in terms of American versus Canadian, and not American versus British, the historical sources of the variants." (p. 5). to support some forms of British usage, as tokens like centre and theatre are spelt the same in both British English and French (Pratt, 1993).

With the presence of so many differing relationships between so-called Canadian forms (here considered as purely British forms for clarity and objectivity) and sociolinguistic variables, the author of this study hypothesizes that a positive relationship exists between Canadian orthographic forms and positive feelings towards Canadian culture. A secondary hypothesis that reinforces the first is that as general knowledge of British and American orthographic forms increases, so does the occurrence of "Canadian" forms. To that end, a descriptive study was constructed to discover the spelling choices, attitudes toward culture and identity, and attitudes towards (and knowledge of) spelling standards by Canadian English variety speakers residing in Saskatchewan so as to find correlations in support of the stated hypotheses.

\section{Materials and Methods}

\subsection{Research Design}

This correlational study aimed at evaluating two relationships (see figure 1) among the three variables selected: the preference of British forms over American forms, attitudes towards Canadian Culture from a Likert scale questionnaire, and results from a British/American form recognition test. The study consisted of three parts. The first part elicited a sample of preferred spelling forms with the help of a short spelling dictation of 25 words. The spelling forms were delivered audibly through a digital sound file and participants were instructed to write what they heard on a simple sheet of 25 blank lines. The second part of the study was based on an original questionnaire, aimed at evaluating the participants' attitudes to Canadian spelling and culture. The questionnaire included seven Likert scale questions about Canadian spelling and culture, as well as general questions about standards, American influence in Canada, and language use. The third part was a short spelling test to evaluate participants' knowledge of British and American forms by showing them a given word and asking them to identify its area of usage - British, American, or both. The original spelling test along with correct answers is presented in Appendix B.

Participants who agreed to take part in this study were provided with two files via email. The first contained a digital copy of all three parts (discussed above) with the instruction to print it before completing it by hand, from beginning to end in chronological order. Hand-writing was required to eliminate the possibility of being influenced by 
digital spelling correction software, and the specific order of the questionnaire minimised the cross-influence of different parts of the questionnaire. The second file contained an audio record of the spelling dictation that the participants were requested to hand-write.

The sampling procedure was Convenience (accessibility of respondents). The population of the undergraduate community of the University of Saskatchewan is typically young (aged 18-25), literate and fluent in English, with at least a high school degree or a basic knowledge of high school subjects. Due to Convenience sampling, the participants may have been more interested in the subject matter than the population, may have been better at spelling than the population, and may have been less indifferent to Canadian culture than the population, either viewing it in a positive light or a negative light.

\subsection{Demographics}

Sample demographics were as follows:

2.2.1 Gender. Demographics of self-reported gender identity among participants.

$\begin{array}{ll}\text { Male } & 10 \\ \text { Female } & 17\end{array}$

\subsubsection{Year of Undergraduate Study. Below} are the number of participants by year of undergraduate degree (by classes taken).

$\begin{array}{ll}\text { 1st year } & 4 \\ \text { 2nd year } & 5 \\ \text { 3rd year } & 5 \\ \text { 4th year } & 11 \\ \text { 4th year+ } & 2\end{array}$

2.2.3 Major. The major pursued (if any) of the sample population.

$\begin{array}{ll}\text { Linguistics } & 12 \\ \text { English } & 2 \\ \text { Psychology } & 2 \\ \text { Food Sciences } & 1 \\ \text { Philosophy } & 1 \\ \text { CMRS +Religion and Culture } & 1 \\ \text { Religion and Culture } & 1 \\ \text { Mechanical Engineering } & 1 \\ \text { Undeclared } & 6\end{array}$

2.2.4 Average age. The average age for the sample.

$\begin{array}{ll}\text { Mean } & 22 \\ \text { Mode } & 21 \\ \text { Median } & 22\end{array}$

2.2.4 First Language. The sample included 24 native Canadian English speakers and 3 non-native speakers:

$\begin{array}{ll}\text { Canadian English } & 24 \\ \text { Ukrainian } & 1 \\ \text { Mandarin } & 1 \\ \text { American English } & 1\end{array}$

For the purposes of testing the hypothesis, only native speakers (NS) were used to test the hypothesis. Nonnative speakers (NNS) were evaluated separately since the preference of Canadian spelling could be affected based on the amount of time spent exposed to Canadian writing institutions - i.e. the number of years spent immersed in Canadian society. However, the NS and NNS combined correlations were computed and are included in Appendix A for transparency.

\subsection{Constructs}
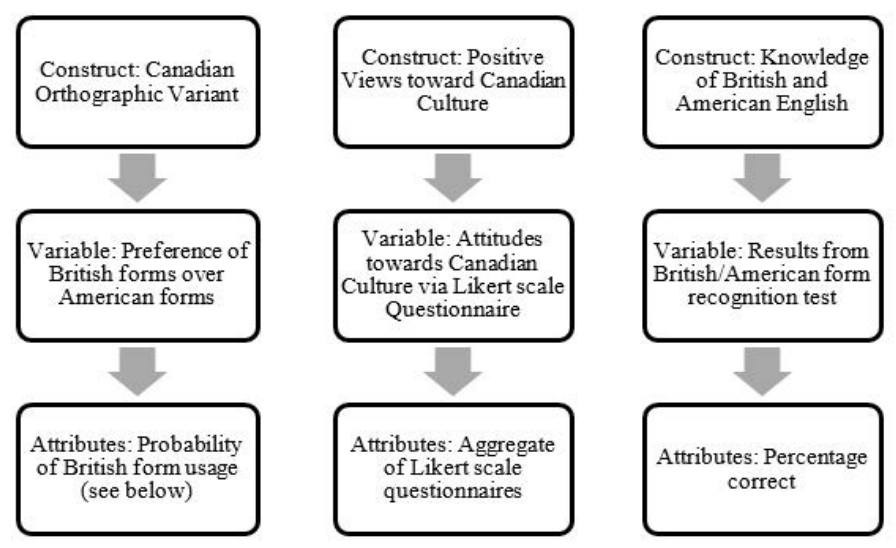

Figure 1. The operationalized constructs as attributes and variables.

Constructs were operationalised as demonstrated by Figure 1. The construct of "Canadian Orthographic Variant" was evaluated by the situations where British standard orthography was used instead of American orthography. 
Preference of British forms over American was simply

Number of British Forms

Number of British Forms + Number of American Forms

or the probability that a word will be spelt the British/Canadian way if it was spelt correctly in either the British or American standard. Culture "consists of knowledge, concepts, and values shared by group members through systems of communication" (Banks \& McGee Banks, 2010, p. 8). The concept of "Positive Views toward Canadian Culture" was measured by converting the given answers from the Likert scale questionnaire to a 1 - 5 system and aggregating the results for each participant. The regional spelling test resulted in a simple score out of $100 \%$ for each participant.
The hypothesis was tested as false or true using a Spearman Rank test. Data analysis was done using Microsoft Excel 2007 and SPSS 21.

\section{Materials}

\subsection{Descriptive Study}

The results of the descriptive study are presented in this section. Please note that the numbers of participants ranged from 26-27 as some results were invalid.

3.1.1 Spelling dictation. The summed results of the spelling dictation are presented below in Table 1. One participant's results were ineligible as answers were produced digitally with aid of spell-checking software. 


\begin{tabular}{|c|c|c|c|c|c|c|c|c|c|c|c|}
\hline 1 & NS & NNS & 7 & & & 14 & & & 19 & & \\
\hline mould & 8 & 2 & centre & 14 & 1 & theatre & 21 & 2 & colour & 21 & 2 \\
\hline mold & 16 & & center & 10 & 1 & theater & 3 & & color & 3 & \\
\hline 2 & & & 8 & & & 15 & & & 20 & & \\
\hline favour & 20 & 1 & paycheque & 15 & 2 & jewellery & 6 & 1 & metre & 13 & 2 \\
\hline favor & 4 & 1 & paycheck & 8 & & jewelry & 11 & & meter & 10 & \\
\hline 3 & & & 9 & & & jewlery & 4 & & (both) & 1 & \\
\hline licence & 4 & 1 & offence & 12 & 2 & jewellry & 1 & & 21 & & \\
\hline license & 14 & & offense & 12 & & jewllery & 1 & & favourite & 18 & 1 \\
\hline lisence & 2 & & 10 & & & jewelery & 1 & & favorite & 5 & 1 \\
\hline liscence & 3 & 1 & analyse & 3 & 1 & jewlry & 0 & 1 & favorate & 1 & \\
\hline lisense & 1 & & analyze & 20 & 1 & 16 & & & 22 & & \\
\hline 4 & & & analize & 1 & & counselling & 15 & 1 & vigour & 17 & 1 \\
\hline axe & 24 & 2 & 11 & & & counciling & 2 & & vigor & 6 & 1 \\
\hline axs & 1 & & litre & 23 & 2 & councilling & 4 & & vigre & 1 & \\
\hline 5 & & & liter & 1 & & councelling & 3 & & 23 & & \\
\hline counsellor & 8 & 1 & 12 & & & counsilling & 0 & 1 & cheque & 24 & 1 \\
\hline counselor & 5 & & pyjamas & 12 & 1 & counseling & 0 & & check & 0 & 1 \\
\hline councillor & 8 & & pajamas & 12 & 1 & 17 & & & 24 & & \\
\hline councellor & 3 & & 13 & & & neighbour & 20 & 2 & levelled & 20 & 2 \\
\hline counsilor & 0 & 1 & dialogue & 22 & 2 & neighbor & 4 & & leveled & 4 & \\
\hline consullor & 1 & & dialouge & 1 & & 18 & & & 25 & & \\
\hline 6 & & & dialoug & 1 & & practice $^{4}$ & 17 & 1 & marvellous & 3 & 2 \\
\hline travelled & 22 & 2 & dialog & 0 & & practise & 7 & 1 & marvelous & 19 & \\
\hline \multirow[t]{2}{*}{ traveled } & 2 & & & & & & & & marvelleous & 1 & \\
\hline & & & & & & & & & marvalous & 1 & \\
\hline
\end{tabular}

Table 1. Descriptive Results. NS= Native Speakers, NNS=Non-Native Speaker 
The results of the dictation indicate that Canadian usage wavers between British and American standards, though there are some examples of consistency. Words that seem specifically entrenched in British usage are cheque, dialogue, litre, theatre, neighbour and axe. Also, inflectional suffixed tokens such as levelled and travelled seem entrenched in traditional British $I$ usage. The participants were slightly more inclined to choose American forms for compounds (paycheque) and morphologically derived forms (such as marvellous)(see below). American influences prevailed among common tokens such as mold, license (as a noun), and jewelry; and also showed an effect on (wavering but still predominately British) tokens such as centre, pyjamas, offence, and metre. There seems little reason why these tokens should be more Americanised than the others; however, one explanation is that they are perhaps slightly more common in everyday speech and therefore more prone to show up in American publications which Canadians read such as The New York Times, books printed and bound in the United States, common websites, etc. As a final note, the -our ending seems more or less stable in Canadian usage while (on the other hand) analyse spelt with a $z$ seems well placed among the participant pool, thus perhaps signalling a permanent departure from the British Standard.

On the inflectional/derivational divide are the spelling forms under counsellor and counselling. There was some confusion among participants as the phonological base counsel- was confused with council(leading to the invention of the verb-form councilling); however, data can still be gleaned. In comparing the British rule of doubling the / grapheme between morphs with the single / American rule, we find that the American rule occurs in 5 out of 26 responses with a derivational suffix (-or) while only 2 out of 26 with an inflectional suffix (-ing). These distributions lead me to believe that the inflectional paradigm is less prone to alteration than the derivational paradigm - possibly because the derivational tokens are introduced into Canadian society based partly on American influenced referents, whereas the inflectional paradigm is a much more grammatical process and thus more resistant to the American variant's influence.

There was a noticeable variation of word spellings among individuals. Longer words were more often non-standard (i.e. wrong) than shorter words; but another interesting development was graphical metathesis, i.e, the reversing of graphical symbols. Words like dialogue were spelt dialouge, and the American token jewelry came out (several times) as jewlery. Also of interest was the spelling of the word licence; participants were presumably attempting to write the American token license but were often confused as to where to put the $s$, thus often placing it as representing the first /s/ phoneme. Participants appeared to know (more or less) what letters were in the word but could not recall their order or the exact specifics of the word structure. Also of note was the problem of how to represent reduced vowels in English; one participant produced vigour as vigre after the litre/metre/theatre pattern, while another participant wrote the (first) $/ \partial /$ in counsellor as a $u$.

There is also some evidence that some participants "split the difference" between the British and American versions: compare jewellry as a blend between jewelry and jewellery or the previous stated example of the form lisence keeping an American s in the word while still having the -ce ending of the British Standard.

\subsubsection{Regional Spelling Test. In addition to the} production of certain words, a test was also attached to evaluate how the participants were able to gauge to which standard (American, British, or both) a list of words belonged (see Appendix B). The results are shown in Figure 2.

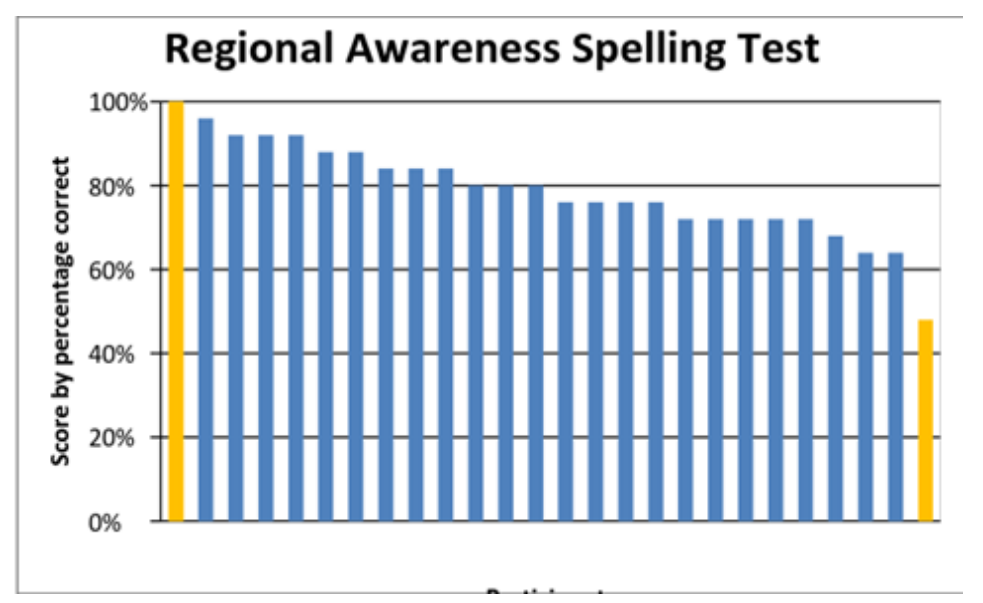

Figure 2. The results of the Spelling Standard recognition test by participant. Non-native speakers are in orange.

Overall, participants seemed reasonably aware of how words were spelt in the British and American standards, though they were by no means consistent in their analysis. For example, the straightforward II rule of British English was ignored as the spelling of "traveler" was repeatedly considered British and even the British -our was sometimes identified as American. It seems that, while students appeared to have an instinctive 
knowledge of each standard, on the consistent application of basic rules they seemed at best average.

This seems to indicate that participants were largely unaware of the particular spelling rules that mark each standard.

3.1.3 Sociological Data. The second part of the study looked at attitudes toward Canadian culture. For the purposes of testing the hypothesis, the results of each question were scored from 1 - 5 and the results summed across all seven questions for each participants; however, the results were by no means uniform. Below are the aggregate data for all data sets.

1: Canadian culture should be presented to the next generation of children through school and/or other activities to preserve the culture.

$\begin{array}{ll}\text { Strongly Agree } & 30 \% \\ \text { Agree } & 59 \% \\ \text { Neither Agree nor Disagree } & 11 \% \\ \text { Disagree } & 0 \\ \text { Strongly Disagree } & 0\end{array}$

2: I find experiences of Canadian culture generally enjoyable.

$\begin{array}{ll}\text { Strongly Agree } & 30 \% \\ \text { Agree } & 63 \% \\ \text { Neither Agree nor Disagree } & 4 \% \\ \text { Disagree } & 4 \% \\ \text { Strongly Disagree } & 0\end{array}$

3: Canadian culture forms an integral part of my identity.

$\begin{array}{ll}\text { Strongly Agree } & 22 \% \\ \text { Agree } & 52 \% \\ \text { Neither Agree nor Disagree } & 22 \% \\ \text { Disagree } & 4 \% \\ \text { Strongly Disagree } & 0\end{array}$

4: Compared to other cultures, Canadian culture offers a unique and worthwhile experience .

$\begin{array}{ll}\text { Strongly Agree } & 22 \% \\ \text { Agree } & 48 \% \\ \text { Neither Agree nor Disagree } & 22 \% \\ \text { Disagree } & 7 \% \\ \text { Strongly Disagree } & 0\end{array}$

5: Canadian culture must be deliberately and carefully preserved.

$\begin{array}{ll}\text { Strongly Agree } & 19 \% \\ \text { Agree } & 26 \% \\ \text { Neither Agree nor Disagree } & 48 \% \\ \text { Disagree } & 7 \% \\ \text { Strongly Disagree } & 0\end{array}$

6: On a daily basis, I am personally affected and impacted in a positive way by Canadian culture.

$\begin{array}{ll}\text { Strongly Agree } & 8 \% \\ \text { Agree } & 63 \% \\ \text { Neither Agree nor } & 26 \% \\ \text { Disagree Disagree } & 4 \% \\ \text { Strongly Disagree } & 0\end{array}$

7: Municipal, provincial and federal governments should take an active role in promoting and protecting Canadian culture in everyday life.

$\begin{array}{ll}\text { Strongly Agree } & 15 \% \\ \text { Agree } & 52 \% \\ \text { Neither Agree nor Disagree } & 26 \% \\ \text { Disagree } & 8 \% \\ \text { Strongly Disagree } & 0\end{array}$

While no participants signalled "Strong Disagreement" to any statement, none objected in any fashion to the prospect of cultural education in the school system (question $\# 1$ ), suggesting some inclination for cultural preservation among participants. By contrast, question $\#_{5}$ received the lowest overall average of any of the questions (see Table 2), even though it arguably presented an idea similar to the first question. Perhaps participants felt that the latter represented a distinctly nationalistic tone.

\begin{tabular}{|l|l|l|l|l|l|l|}
\hline 1 & 2 & 3 & 4 & 5 & 6 & 7 \\
\hline 4.19 & 4.19 & 3.93 & 3.85 & 3.56 & 3.74 & 3.74 \\
\hline
\end{tabular}

Table 2. Average Likert scale scores by question.

The average Likert scale scores show that participants were slightly more reticent about two of the statements: one on governmental interference (question \#7) and one on the daily personal impact of Canadian culture (\#6). This seems to indicate that while people enjoy Canadian culture and think that it should be preserved, they also do not wish to sign a blank cheque to the effect. 


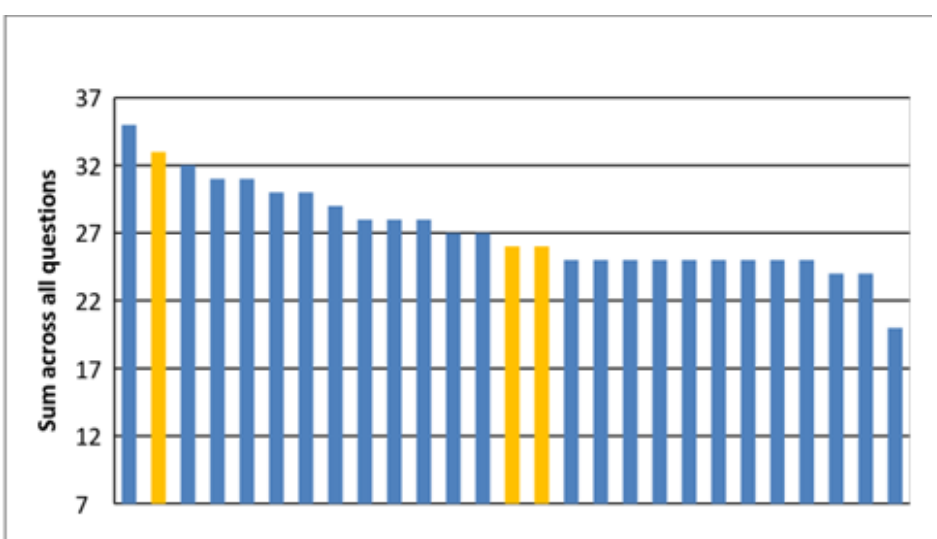

Figure 3. Sum of Likert scales by participant. Non-native speakers are in orange.
The aggregate data for all Likert scale questions is presented above in Figure 3 across all data sets. Please note that the lowest "score" is $7\left(7 *_{1}\right)$ while the highest possible is $35(7 * 5)$. Thus, all data sets are distributed within this range. It should also be noted that all of the questions received an overwhelmingly positive response only 1 participant scored less than the neutral 21 (i.e., 7 * 3).

3.1.4 Self-reported use/preference for

-our spellings. The aggregate data concerning participants' -our spelling preferences (via self-reporting questionnaire) was recorded and is presented in Table 3 and Table 4.

\begin{tabular}{|l|l|l|l|l|}
\hline USE & Always (\%) & Sometimes (\%) & Never (\%) & Don't Notice (\%) \\
\hline Facebook/ internet-based social networking & 79 & 8 & 13 & 0 \\
\hline Emails & 83 & 4 & 13 & 0 \\
\hline English papers & 88 & 4 & 8 & 0 \\
\hline $\begin{array}{l}\text { Correspondence with professors/ other members of } \\
\text { social privilege }\end{array}$ & 83 & 13 & 4 & 0 \\
\hline PREFERENCE & & & & \\
\hline Titles for books, movies, etc. & 46 & 25 & 0 & 29 \\
\hline Books & 54 & 25 & 0 & 21 \\
\hline Newspaper articles & 67 & 13 & 0 & 21 \\
\hline Blog posts & 46 & 21 & 4 & 29 \\
\hline Personal correspondence from friends & 58 & 21 & 4 & 17 \\
\hline $\begin{array}{l}\text { Personal correspondence from professors/ other } \\
\text { members of social prestige }\end{array}$ & 54 & 29 & 0 & 17 \\
\hline
\end{tabular}

Table 3. Self-reported use of -our spellings of Native Speakers.

\begin{tabular}{|l|l|l|l|l|}
\hline USE & Always (\%) & Sometimes (\%) & Never (\%) & Don't Notice (\%) \\
\hline Facebook/ internet-based social networking & 67 & 0 & 33 & 0 \\
\hline Emails & 67 & 33 & 0 & 0 \\
\hline English papers & 100 & 0 & 0 & 0 \\
\hline $\begin{array}{l}\text { Correspondence with professors/ other members of } \\
\text { social privilege }\end{array}$ & 100 & 0 & 0 & 0 \\
\hline PREFERENCE & & & & \\
\hline Titles for books, movies, etc. & 67 & 0 & 33 & 0 \\
\hline Books & 67 & 0 & 33 & 0 \\
\hline Newspaper articles & 67 & 0 & 33 & 0 \\
\hline Blog posts & 67 & 0 & 33 & 0 \\
\hline Personal correspondence from friends & 67 & 0 & 33 & 0 \\
\hline $\begin{array}{l}\text { Personal correspondence from professors/ other } \\
\text { members of social prestige }\end{array}$ & 67 & 0 & 33 & 0 \\
\hline
\end{tabular}

Table 4. Self-reported use of -our spellings of Non-Native Speakers. 
The highest use of the -our endings was in English papers [even though in our previous two examples (see section 1.1) students were allowed to choose between American and British standard spelling', while the lowest use of-our spellings was on internetbased social networking. Somewhat more surprising is the high preference of-our spelling in newspapers, thus suggesting that participants want to see "Canadian spelling" (or at the very least, the -our spelling) while participating in social discourse. On the whole, however, participants were more blasé about seeing the -our spelling than producing it, suggesting that perhaps there is some degree of linguistic tolerance in the sampling frame. At the same time that it offers an opportunity to study the classic cornerstone of Canadian spelling, this data also represents the dichotomy between what speakers produce and what they expect to see.

\subsubsection{Survey on Canadian linguistics and}

related areas. The last survey in part II related to general questions on Canadian linguistics and orthography. Questions centered around what are the stated spelling preferences, attitudes toward Canadian English, and thoughts on its preservation.

On the question of whether or not a participant could identify a word in Canadian English that comes from British or American English $79 \%$ of the native speakers answered that they could. Data for their preferences is presented in Table 5.

\begin{tabular}{|l|l|l|l|}
\hline Spelling Preferences & Native Speakers & Non-Native Speakers & $\begin{array}{l}\text { Average Probability of British Forms } \\
\text { (from Part 1) }\end{array}$ \\
\hline Canadian & 18 & 2 & 0.69 \\
\hline American & 2 & 1 & 0.53 (only 2 data sets) \\
\hline British & 1 & 0 & 0.62 \\
\hline British and Canadian & 1 & 0 & 0.82 \\
\hline American and Canadian & 1 & 0 & 0.72 \\
\hline No preference & 1 & 0 & 0.52 \\
\hline
\end{tabular}

Table 5. Spelling standard preferences among participants.

As Table 5 demonstrates, participants clearly state the "Canadian" spelling system as their number one choice. However, figure 4 shows that the correlation seems only marginally backed by the numbers.

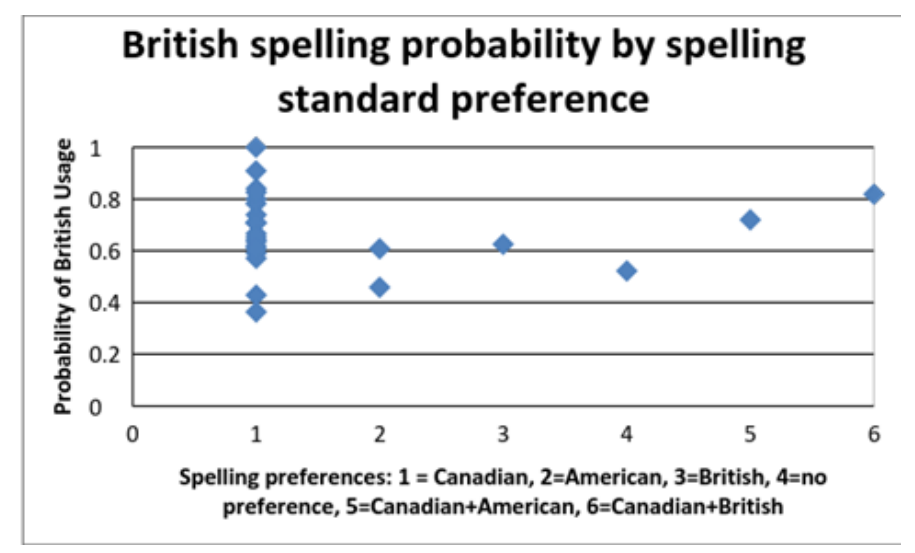

Figure 4. Probability of producing British forms versus stated spelling standard preferences.
As can be seen, there are very few data sets to represent any correlation. The correlation that is represented, however, is similar to the main hypothesis; namely that positivity toward Canadian culture (in this case, represented by a "Canadian language") results in an increase of British form usage in the spelling dictation.

A related issue to Canadian nationalism is antiAmericanism. Participants were surveyed as to how American culture was impacting Canadian culture, as Table 6 shows. 


\begin{tabular}{|l|l|l|}
\hline $\begin{array}{l}\text { The effect of American } \\
\text { culture is: }\end{array}$ & $\begin{array}{l}\text { Native } \\
\text { Speakers }\end{array}$ & $\begin{array}{l}\text { Non-Native } \\
\text { Speakers }\end{array}$ \\
\hline Very positive & 0 & 1 \\
\hline Mainly positive & 3 & 1 \\
\hline Neutral & 12 & 1 \\
\hline Mainly negative & 7 & 0 \\
\hline Very negative & 0 & 0 \\
\hline No effect & 2 & 0 \\
\hline
\end{tabular}

Table 6. Spelling standard preferences among participants.

The view is surprisingly centred around the "neutral" response, as no NS answered either "very negative" or "very positive". While attitudes were more inclined to an anti-American viewpoint, thus indicating an antiAmerican bias in the participant pool, when analysing the data it is difficult to see a correlation (see figure 5). This seems to indicate that at least with reference to this particular study - i.e., studying the spelling preferences of Canadians using a spelling dictation - there is no relation found between stated anti-Americanism and increased probability of British forms.

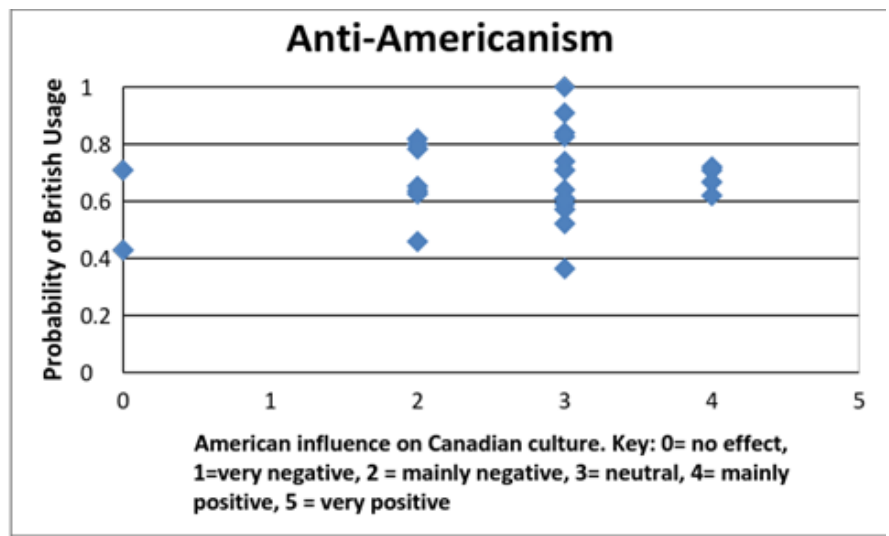

Figure 5. Anti-Americanism and the probability of British usage.

Here, we see presented the relationship between antiAmericanism and British form usage among participants. As stated earlier, there does not seem to be any observable relationship.

Returning to the topic of Canadian linguistics, the majority (96\%) of NS participants and all NNS felt that Canada had its own unique version of English. 21 out of 23 NS participants felt that Canada expressed its individuality in its vocabulary, 21 through its spelling, and 18 through its distinctive accent; though it is worth mentioning that all three NNS felt that Canada had its own audible accent. Other suggestions from participants for distinctive Canadian situations were a unique sentence structure and language contact blends such as "Ukrenglish" or "Franglais".

When asked how to the preserve this Canadian variant, ${ }^{5}$ six participants suggested that Canadian English was "doing fine" and needed no preservation, while 11 felt that things should be left free to develop without intervention. One student stated, "being free to choose which variant to use is Canadian" while one commented that "you can't preserve a language in its current state." Another student suggested that there were many Canadian English variants and that no single one should be preferred. Among those who wished to preserve it, three wanted it codified, nine wished for it to be taught in schools, while four suggested that portrayal on outlets such as television was the right way to go. Additionally, one student suggested that regional variations were important (a contrast with the focus on a single national standard) and another suggested further study. Two students suggested that online spell checkers were a good way to assure language preservation, taking the language preservation argument into the digital age.

\subsection{Correlational Analysis}

This study's main purpose was to attempt to find correlations between positive Canadian feelings toward Canadian culture and increased British (Canadian) form usage, and between greater awareness of American/British spelling standards and increased British form usage. Of course, other possible correlations can be drawn from the data.

3.2.1 Other Correlations. Before testing the two hypothesis, we will look at some possible other correlations: age, gender (see Table 7), year of undergraduate study, and major (please note: antiAmericanism bias has already been presented, see Figure 5). Figure 6 shows the correlation between age and British form usage.

${ }^{5}$ Please note: participants signalled more than one suggestion and some participants wrote none. Also note that some students signalled that Canadian English was doing fine without expressed neutrality and vice versa. Each number is out of 26 as one participant did not feel that Canada had its own unique version of English.

University of Saskatchewan Undergraduate Research Journal 


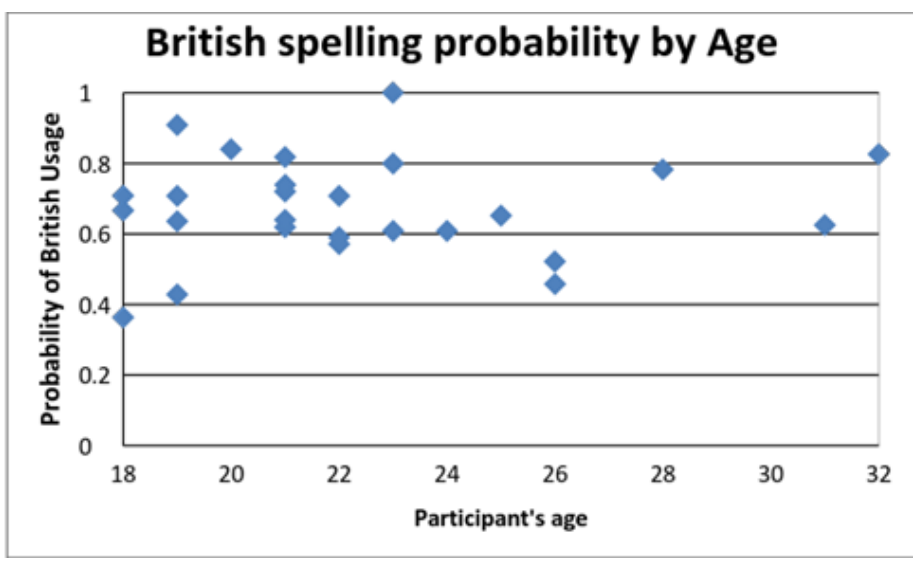

Figure 6. Correlation between British spelling forms and the age of the sample.

There is no correlation for the span of this age group between British form usage and age. If there were a relationship between british spelling and age, it would imply a possible language shift as older generations represent a previous features of any given language while younger generations tend represent the future features ( Holmes, 2012); as it is, it seems to imply that the British form usage is stable over the participant age range (between 18 and 32). Pearson Rank correlations did not produce any significant results.

Table 7 shows the arithmetic mean by gender of respondents.

\begin{tabular}{|l|l|}
\hline Male (9) & 0.705665 \\
\hline Female (17) & 0.658846 \\
\hline
\end{tabular}

Table 7. Probability of British forms by gender.

While males have a higher probability for British form usage, there doesn't seem to be enough of a difference between genders to affect the results of the study, though the difference may suggest that males are more conservative when it comes to this instance of language use.

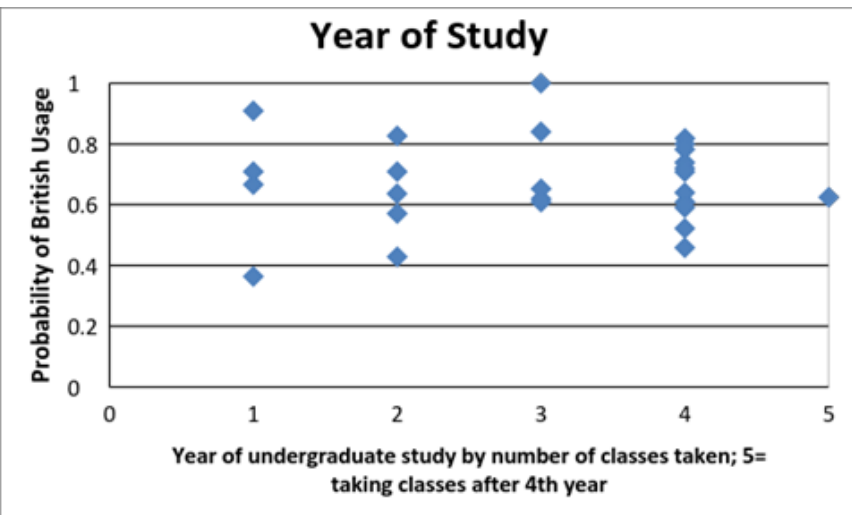

Figure 7. Correlation between British spelling forms and year of study.

As Figure 7 shows, there is no relation between a participant's year of undergraduate study and his or her spelling preferences. If the educational system has an effect upon a participant's spelling (as Warkentyne suggested (1979), it seems to be at an earlier stage (or the observable influence does not occur within the timeframe of undergraduate study).

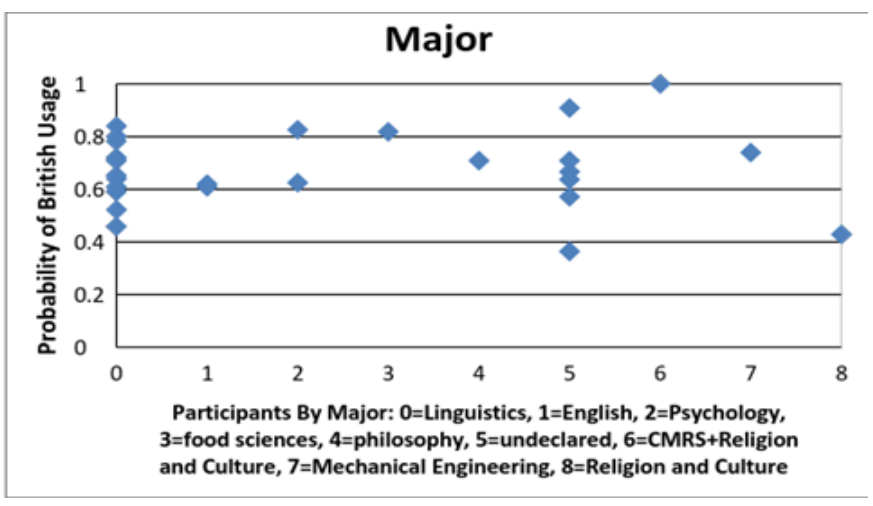

Figure 8. Correlation between British spelling forms and participant's major (CMRS=Classical, Medieval and Renaissance Studies, a program offering at the University of Saskatchewan).

As Figure 8 demonstrates, there also seems to be little effect on British usage based on major. Nonetheless, for the purposes of this study, convenience sampling does not appear to have radically altered the sampling frame, as there seems no quantifiable difference between participants based on their majors.

\subsubsection{The Correlational Study. Below are} the results of the correlational study created using the results of the descriptive study.

3.2.2.1 The hypothesis. The original hypotheses state that there will be a correlation found in two areas; 
namely that there will be a positive correlation found between British form usage and positive attitudes toward Canadian culture, and that there will be a positive correlation between British form usage and knowledge of British and American spelling standards. Both observations show extra linguistic motives at work in Canadian orthography, and that positive views of Canadian culture positively effect preference for the British forms.

A Spearman rank test was chosen to test the two correlations based on the data from the descriptive study. Native speakers were evaluated separately (results for combining NS and NNS are presented in Appendix A). A 0.42 correlation was found between the sum of Likert Scale questions on Canadian culture and the probability of British spelling over American ( $p$-value of <.05). For the correlation between the probability of British spelling and the test scores from the regional awareness spelling test, a correlational coefficient of .66 was found (with a $p$ value of <.01).

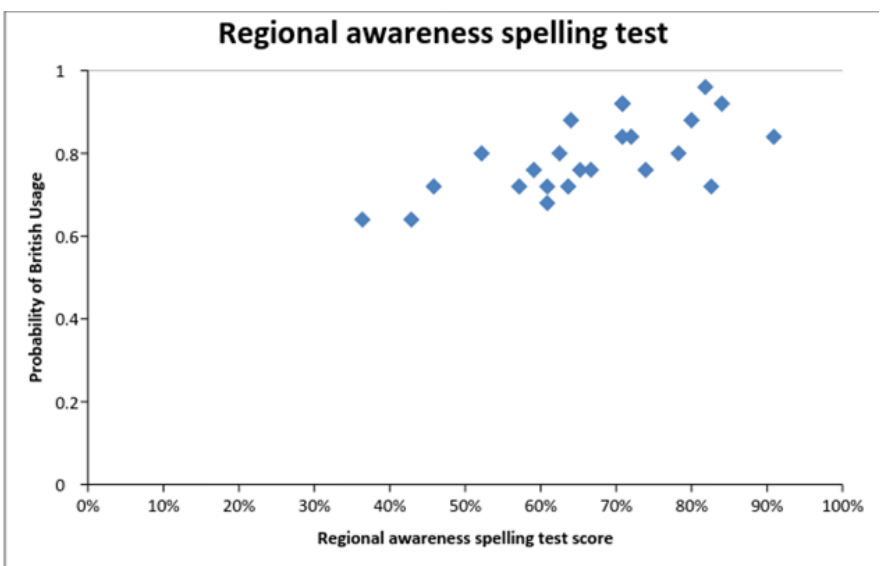

Figure 9. The first correlation between views on Canadian culture and British forms. As figure 9 demonstrates, data sets on British forms and Likert scale responses were found to be upward sloping.

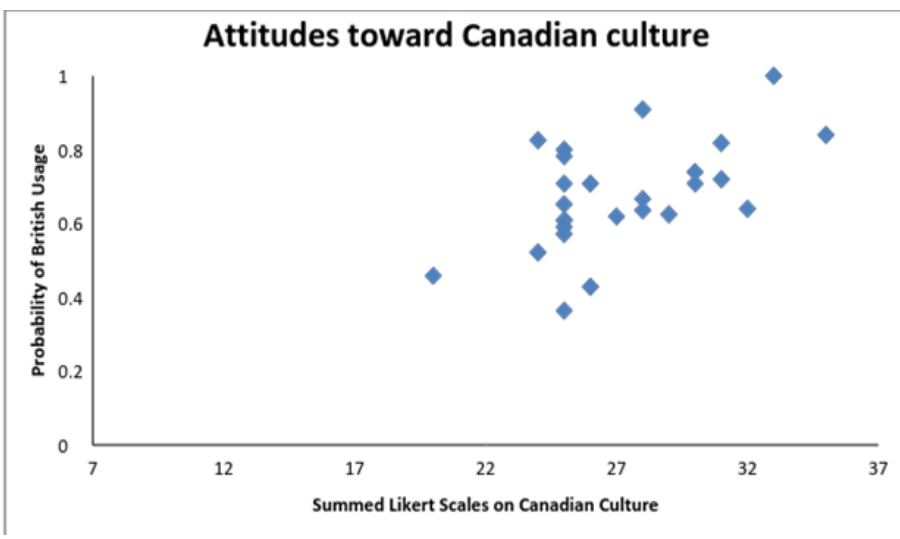

Figure 10. Probability of British forms versus regional spelling test.

Again, as Figure 10 demonstrates, the upward sloping data indicates positive relationship between participant awareness and use of British forms. This indicates extralinguistic motives at work as there seems a desire present to follow the British standard (or at the least a more British standard specific to each participant). Once this knowledge is attained, spelling choices are affected. 


\begin{tabular}{|lll|r|}
\hline & & & $\begin{array}{c}\text { Probability of } \\
\text { British Spelling } \\
\text { Over American }\end{array}$ \\
\hline Spearman's rho & Probability of British Spelling Over American & Correlation Coefficient & 1.000 \\
& & Sig. (2-tailed) &. \\
\cline { 2 - 4 } & & $\mathrm{N}$ & 24 \\
\cline { 2 - 4 } & Regional spelling test & Correlation Coefficient & $.660^{-}$ \\
& Sig. (2-tailed) & .000 \\
& & $\mathrm{~N}$ & 24 \\
\cline { 2 - 4 } & Likert Scale Sum & Correlation Coefficient & $.422^{-}$ \\
& & Sig. (2-tailed) & .040 \\
& $\mathrm{~N}$ & 24 \\
\hline
\end{tabular}

Table 8. The data output from SPSS Pearson Rank correlation test.

**. Correlation is significant at the 0.01 level (2-tailed)

*. Correlation is significant at the 0.05 level (2-tailed)

As the correlation test from Table 8 shows, the results of the Spearman rank test on the British form and Likert Scale Sum, and British form and regional spelling awareness correlations. The results indicate a moderate relationship for the former (significant to the 0.05 level) and a strong relationship for the latter (significant to the 0.01 level).

\section{Discussion}

\section{The Positive Attitudes toward Canadian Culture Correlation}

The first hypothesis presented was that there would be a positive correlation between positive attitudes toward Canadian culture and usage of the British (taken as Canadian) form. This hypothesis passes, albeit as only a "moderate" correlation. This is not surprising, as historically no single factor seems to completely dominate the choice to spell things "the Canadian way." Canadians who are instinctively more positive toward their Canadian culture are also instinctively more likely to want to use the forms which they perceive to be specially "Canadian," though it would be interesting to see if tokens like analyse and mould are perceived as being Canadian (because of their presence in the British standard) or British (as the American standard forms, analyze and mold, seem to be more common for these particular words).

It should also be noted that among participants there were some signals that linguistic nationalism or prescriptivism was undesirable as almost half of participants (11 out of 23 , see section 3.1 .5 ) in this sample thought that Canadian English should be left free to develop without interference. Others seemed more open to the possibility of a national standard variety through codification and education within the paradigm of the school system. Since there may have been a slight bias against linguistic prescriptivism in the participant pool (12 out of 26 were Linguistics majors) the latter view - that codification and education were important - might be found to be the majority view of Canadians in further study.

\section{The Regional Awareness Spelling Test Correlation}

The second hypothesis maintains that when there is a greater knowledge of British and American Standards (i.e., education about English standards), there will be a greater preference for British forms. In support of this hypothesis, a strong correlation was found between the probability of British forms appearing on the spelling dictation and the higher score received on the American and British spelling test. This correlation suggests that when there is basic knowledge of American or British word forms, there is an increased use of the word forms perceived to be Canadian. This implies two statements. One, while people are willing to use the more "Canadian" orthography (British standard orthography) in their written speech, they may be unable to because they fail to recall or are unaware of the etymology of each word's distinctive spelling. Two, extra-linguistic motives are at work, as the etymology of the standard form forms a central part of the actual conscious or unconscious decision-making process in the language use. In other words, as people know more about spelling standards, they are seen to use prefer the British system, at least in this limited sample. 


\section{Canadian Spelling?}

The biggest upshot of the spelling dictation is the non-standard response rate along two lines. The first is that participants were often inconsistent in how they applied and perceived -our, -re or -ll- spellings. The variation in Canada is not simply from speaker to speaker but within each speaker's spelling lexicon (though this might change if a greater emphasis on basic education concerning American/British spelling forms were pursued). It seems that currently no consistent solution for a Canadian standard could be found even if there were only one single speaker taken to represent the standard for Canada, as he or she might likely change his or her spelling practices with no discernible linguistic or extralinguistic pattern. The second observation is that most speech communicators do not seem to have the ability to consistently handle the minute spelling decisions at the heart of this dichotomy. When it comes to written speech production, many respondents could not recall the exact order of all the l's, e's, and r's, in the token jewellery, for example, regardless of where their sentiments lie in the realms of language and culture. Even without considering the cross-linguistic interference represented by competing standards, this issue of spelling consistency and the difficulty this causes for adherence to any standard seems to be the basic problem behind any proposed solution.

What can be done to resolve this issue? Excluding a return to the a better sound-spelling correspondence represented by Old English orthography or Middle English spelling reform (see section 1.2), there seems to be no golden standard to refer to, as everything at this point seems unavoidably arbitrary. Setting aside these issues, the basic intuition for a solution within the Canadian linguistic paradigm has us picking a dialect - for instance, Ontario's - and developing from there through the three remaining stages of standard language development (see section 1.1). Assuming that codification can resolve basic spelling differences (though, as we have seen from this descriptive study, litre seems cemented in the -re ending while metre seems to be wavering between the -re and -er paradigms), and assuming that any dialect in Canada could undergo "elaboration" through study in the private sector (dictionaries) or through public funding (university level grants for student and professional researchers), we still come face to face with the "acceptance" stage. It is unlikely that any modern speech community will easily agree on anything linguistically related, let alone something as controversial as a new spelling standard. Seen from this perspective, Canadian spelling, as an idea, seems condemned to limp on indefinitely, afraid to be overly questioned, with more and more American forms and spelling deviations creeping in when no old-fashioned grammarians or editors are watching closely.

However, I do not necessarily believe that this future is unavoidable. The public's awareness needs to be drawn as to what standards are, why they exist, and both the good and the bad that can happen when they are presented in a social framework. When there exists the understanding that linguistic standards are meant to streamline modern communication (see Haas, 1982, p. 34-35) while also taking into account the necessity of minimising the negative effects brought by standards such as barriers to education and employment for "nonstandard" speakers (or writers in the context of this paper), a new standard may be presented without, hopefully, many of the more negative social realities we have come to expect surrounding one nation, one language methodologies (see Davies, 2012). In the final analysis, standards are as standards do, and if the negative social realities associated with "correct" language use can be minimised we can move forward to a scenario where a province's (like Saskatchewan's) acceptance of a foreign dialect's standard (such as Ontario's) is not an unacceptable solution to a basic communication problem.

\section{International Versus World English}

\section{Standards?}

Another issue that concerns standards is the situation in World English communities that do not necessarily conform to British or American standards. In fact, the concept of "World Englishes" holds that there are many different varieties of English (Hamps-Lyons and Davies, 2008), each one with presumably as much right to have its own standard as any other. However, as we have seen, it is difficult for any dialect or variety to attain the social prestige necessary to become accepted - in the case of World Englishes, they must also compete with British and American standards (see Hamps-Lyons and Davies, 2008). 
Canada is in a similar situation, at least in the sense of being sandwiched between competing standards. The task of competing with such towering giants of American and British standard orthography and attempting to forge a new standard seems from the outset as an all but unassailable goal - how many school texts, government documents, spellers (digital and printed) would have to be rewritten? How many educators would have to be re-educated, how many editors and secretaries retrained, and how many school boards would have to be convinced to embrace the new standard? The cost seems, at least at the outset, to be staggering. Trying to gather support for a published standard that differs from the American or British standard is thus not likely to be met with much success.

What then can be done to counter this linguistic inertia? With respect to standard language tests, Davidson (2006) suggests that gathering and processing empirical data from native speakers of a given World English into a standard for testing would resolve the World Englishes testing bias by moving the standard from outside to within a given speech community. Therefore, one solution is to find some way of streamlining the development of orthographic standards to the point where speakers of any language or dialect can seamlessly gather data and process them into standards, the result being a process that respects both community needs and the desire to represent the linguistic unity of the community in a social standard. This transparency is at least needed to show that a proposed standard is not simply a power grab by some members of a speech community to supplant others.

A second idea is the actual will to change. Handling the issue of standardisation of World Englishes, Davies (2009) posits that "if WEs are to strike out for their own norms, that is a choice that they must make. Only their own uncertainty prevents them" (p. 87). Assuming the Canadian linguistic community is in the same predicament, is Canadian English merely uncertain? Or is there something else at work? This paper (and in others; see section 1.4) finds differing motives for a "Canadian English": the will is certainly there, only the practical workings of a standard (see section 1.2) are missing.

This paper began by discussing two ideas: the specific 500-year-old dialect upon which English orthography is based, and the phenomenon of "standard language cultures." The first case holds the slightly absurd proposition of forcing English as a Foreign
Language learners to read and graphically record spelling symbols that represent a spoken language which is not modern English - it is essentially a form of middle English (see Cook, 2014). The second case holds the idea, so often assumed a linguistic universal, that non-standard variation must always carry a linguistic taboo while correct language use must be a marker for social elevation (Vogl, 2012). By contrast, the reality is that for EFL speakers, intelligibility is paramount over correctness (Davies, 2009, p. 85), an idea with a real-world referent that is not an entirely fictional one as has been levied at the nationalistic concept of "Canadian English" (see Lilles, 2000; Upward, 2000). If this is true for EFL speakers who are often using English as a kind of new "Lingua franca" (see Davies, 2009), it may be that the future of English orthography is not found in devotion to an unchanging standard; instead, it may be found in a new, ever-more creative attempt to problem-solve language and social discourse-related problems through creative compromise. If this is true, orthography may one day be moulded to serve a speech community's benefit, and not the other way around. 


\section{References}

Aden Bowman Collegiate Student Handbook 2013-2014. (2013). Retrieved, March 31, 2014, from http://www.spsd.sk.ca/school/adenbowman/Abo ut/handbook/Documents/

Anson, C. (1990). Errours and Endeavors: A Case Study in American Orthography. International Journal of Lexicography, 3(1), 35-63.

Banks, J. A. and McGee Banks, C. A. (2010). Multicultural Education (7th ed.). Hoboken, NJ: John Wiley \& Sons.

Baugh, A. C. and Cable, T. (2002). A History of the English Language (5th ed.). London, England: Routledge.

Cook, V. (2014). The English writing system. London, England: Routledge.

Davies, A. (2009). Assessing world englishes. Annual Review of Applied Linguistics. (29), 80-89.

Davies, W. V. (2012). Myths we live and speak by: Ways of imagining and managing language and languages. In Hüning, M., Vogl, U. \& Moliner, O. (Eds.), Standard Languages and Multilingualism in European History (45-70). Amsterdam: John Benjamins Publishing.

Dolinger, S. (2011). Academic and public attitudes to the notion of 'standard' Canadian English: On Standard Canadian English, those who speak it, those who study it, and those who discuss it. English Today, 108(27), 3-9.

Gregg, R. J. (1989). La lexicographie de l'anglais canadien. Revue québécoise de linguistique, 18(01), 151186.

Grue, D. (2014). Testing Canada's 'honour': Does orthography index ideology? Strathy Student Working Papers on Canadian English.

Haas, W. (1982). Introduction: On the normative character of language. In Haas, W. (Ed.), Standard languages: spoken and written (1-36). Manchester, England: Manchester University Press.
Hamp-Lyons, L., \& Davies, A. (2008). The Englishes of English tests: Bias revisited. World Englishes, 27(1), 26-39.

Heffernan, Borden, Erath \& Yang. (2010). Preserving Canada's 'honour.' Written Language \& Literacy, 13(1), 1-23.

Holmes, J. (2013). An Introduction to Sociolinguistics (4th ed.). New York, NY: Routledge.

Lipski, J. M. (1976). Orthographic variation and linguistic nationalism. La Monda Lingvo-Problemo, 6(16), 37-48.

Milroy, J. (2001). Language ideologies and the consequences of standardization. Journal of Sociolinguistics. 5(4). 530-555.

Lilles, J. (2000). The myth of Canadian English. English Today, 16(02), 3-9.

Noah Webster and America's First Dictionary. (n.d.). Retrieved March 31, 2014, from http://www.merriamwebster.com/info/noah.htm

Noah Webster's Spelling Reform. (n.d.). Retrieved March 31, 2014, http://www.merriamwebster.com/info/spelling-reform.htm

Pratt, T. K. (1993). The hobgoblin of Canadian English spelling. In Focus On Canada, (4564).Amsterdam, the Netherlands: John Benjamins B.V.

Public Works and Government Services Canada. Translation Bureau. (1997). The Canadian Style: A Guide to Writing and Editing. Toronto: Oxford.

Ramsey, S. (2012) Cultural persuasion in lexicographical space: Dictionaries as site of nineteenthcentury epideictic rhetoric. Rhetoric Review, 31(1), 64-8o.

Requirements For Essays. (2014). Retrieved March 31 From http://artsandscience.usask.ca/english/pdf/Requi rementsForEssays.pdf 
Scragg, D. G. (1974). A History of English Spelling.

Manchester University Press.

Skorupska, A. (2013). Canadian English: A study of variation in Canadian English spelling and the spelling policies of Canadian newspapers. GRIN Verlag.

Shuttleworth, R. (2011). Computer language settings and Canadian spelling. TESL Canada Journal/Revue TESL du Canada, 29(01), 121-130.

Upward, C. (2000). Canadian spelling choices. English Today, 4, 20-21.

Vacheck, J. (1982). English orthography: A functionalist approach. In Haas, W. (Ed.), Standard Languages: Spoken and Written (37-56). Manchester: Manchester University Press.

Warkentyne, H. J. (1971). Contemporary Canadian English: A report of the Survey of Canadian English. The American Dialect Society, 46(3/4).

Vogl (2012). Multilingualism in a standard language culture. In Hüning, M., Vogl, U. \& Moliner, O. (Eds.), Standard Languages and Multilingualism in European History (1-42). Amsterdam: John Benjamins Publishing. 


\section{Appendices}

\section{Appendix A}

Correlations across all data sets (NS and NNS)

Table A1.

Data output from SPSS Pearson Rank correlation test.

\begin{tabular}{|c|c|c|c|}
\hline & & & $\begin{array}{l}\text { Probability of } \\
\text { British Spelling } \\
\text { Over American }\end{array}$ \\
\hline \multirow[t]{3}{*}{ Spearman's rho } & Probability of British Spelling Over American & $\begin{array}{l}\text { Correlation Coefficient } \\
\text { Sig. (2-tailed) } \\
\mathrm{N}\end{array}$ & $\begin{array}{r}1.000 \\
. \\
26 \\
\end{array}$ \\
\hline & Regional spelling test & $\begin{array}{l}\text { Correlation Coefficient } \\
\text { Sig. (2-tailed) } \\
\mathrm{N}\end{array}$ & $\begin{array}{r}.476^{\circ} \\
.014 \\
26 \\
\end{array}$ \\
\hline & Likert Scale Sum & $\begin{array}{l}\text { Correlation Coefficient } \\
\text { Sig. (2-tailed) } \\
\mathrm{N}\end{array}$ & $\begin{array}{r}.494^{\circ} \\
.010 \\
26\end{array}$ \\
\hline
\end{tabular}

Here, across all 26 valid data sets (both NS and NNS) both hypotheses pass as a moderate correlation; the correlation between British spelling and positive views of Canadian culture is 0.49 , while the other correlation between the regional awareness spelling test and British spelling is 0.48 . Both have p-values $<0.05$. 
Appendix B (correct answers highlighted)

Some of the following words are spelt differently in American and British orthography (and some are spelt exactly the same). For each of the following words, circle which region this particular spelling is (usually) found in.

\begin{tabular}{|c|c|c|c|}
\hline dreamt & American & British & Both \\
\hline storey & American & British & Both \\
\hline tyre & American & British & Both \\
\hline jail & American & British & Both \\
\hline vigorous & American & British & Both \\
\hline endeavor & American & British & Both \\
\hline error & American & British & Both \\
\hline theater & American & British & Both \\
\hline troubling & American & British & Both \\
\hline worldly & American & British & Both \\
\hline cancelled & American & British & Both \\
\hline traveler & American & British & Both \\
\hline humour & American & British & Both \\
\hline neighbour & American & British & Both \\
\hline manoeuvre & American & British & Both \\
\hline jewellery & American & British & Both \\
\hline$a x$ & American & British & Both \\
\hline analyze & American & British & Both \\
\hline cheque & American & British & Both \\
\hline gaol & American & British & Both \\
\hline plow & American & British & Both \\
\hline favorite & American & British & Both \\
\hline labor & American & British & Both \\
\hline pyjama & American & British & Both \\
\hline mirror & American & British & Both \\
\hline
\end{tabular}

